\title{
PENGARUH PENERAPAN STANDARD OPERATING PROCEDURE (SOP) DAN KEBIJAKAN PERTANIAN TERHADAP EFEKTIVITAS LAYANAN SUB TERPMINAL AGRIBISNIS (Studi Kasus di UPTD Sub Terminal Agribisnis dan Agropolitan Cigombong, Kecamatan Pacet, Kabupaten Cianjur)
}

\author{
Oleh : \\ Adang Suryana*) \\ Endah Lisarini**) \\ Arisha Konita Larasati***) \\ Email : dian adang@yahoo.co.id dan endahlisarini@yahoo.com
}

\begin{abstract}
ABSTRAK
Sub Terminal Agribisnis (STA) merupakan suatu tempat/sarana pemasaran yang dibangun secara spesifik untuk melayani dan melaksanakan kegiatan distribusi dan pemasaran hasil petanian petani/pelaku usaha pertanian dari sumber produksi ke lokasi tujuan pemasaran. Dalam melakukan distribusi tidak terlepas dari keberadaan Standard Operating Procedure (SOP) untuk mengurangi kesalahan dalam setiap pelaksanaannya. STA di Kabupaten Cianjur berjalan berdasarkan Peraturan Bupati Cianjur Nomor 02 tahun 2018 tentang pembentukan Unit Pelaksana Teknis Daerah (UPTD) di lingkungan pemerintah Kabupaten Cianjur. Tujuan penelitian ini adalah : (1) Untuk mengkaji pengaruh SOP terhadap efektivitas layanan STA; (2) Untuk mengkaji pengaruh kebijakan pertanian terhadap efektivitas layanan STA; dan (3) Untuk mengkaji pengaruh simultan SOP dengan kebijakan pertanian terhadap efektivitas layanan STA. Data dikumpulkan dari 66 orang petani pemasok sayuran ke pelaku usaha di STA untuk didistribusikan kembali ke pasar tradisional. Analisis data yang digunakan adalah analisis jalur dengan hasil yang didapat pada penelitian ini adalah SOP berpengaruh signifikan terhadap efektivitas layanan STA, kebijakan pertanian berpengaruh signifikan terhadap efektivitas layanan STA, dan SOP dengan kebijakan pertanian berpengaruh signifikan secara simultan terhadap efektivitas layanan STA.
\end{abstract}

Kata Kunci : Standard Operating Procedure (SOP), kebijakan pertanian, efektivitas layanan, Sub Terminal Agribisnis.

\section{ABSTRACT}

Sub Terminal Agribisnis (STA) is a place / marketing facility built specifically to serve and carry out distribution and marketing activities for farmers / agricultural business actors from production sources to marketing destination locations. In conducting distribution, it is inseparable from the existence of Standard Operating Procedures (SOP) to reduce errors in each implementation. STA in Cianjur Regency runs based on the Cianjur Regent Regulation Number 02 of 2018 concerning the establishment of a Unit Pelaksana Teknis Daerah (UPTD) in the Cianjur Regency government environment. The objectives of this study are: 1) To assess the effect of SOPs on the effectiveness of STA services; (2) To assess the effect of agricultural policies on the effectiveness of STA services; and (3) To study the simultaneous effect of SOP with agricultural policies on the effectiveness of services. The data are collected from 66 farmers who supply vegetables to businesses at

\begin{tabular}{llc}
\hline PENGARUH & PENERAPAN & STANDARD \\
OPERATING & PROCEDURE & (SOP) DAN \\
KEBIJAKAN & PERTANIAN & TERHADAP \\
EFEKTIVITAS LAYANAN SUB & TERMINAL \\
AGRIBISNIS (Studi Kasus di UPTD Sub \\
Terminal Agribisnis dan Agropolitan Cigombong, \\
Kecamatan Pacet, Kabupaten Cianjur)
\end{tabular}

ADANG SURYANA, ENDAH LISARINI dan ARISHA KONITA LARASATI 
STA to be distributed back to traditional markets. The data analysis used is path analysis with the results obtained in this study is the effect of SOP has a significant effect on the effectiveness of STA services, the effect of agricultural policies has a significant effect on the effectiveness of STA services, and the simultaneous effect of SOP with agricultural policies has a significant effect on the effectiveness of STA services.

Keywords : Standard Operating Procedure (SOP), agricultural policy, service effectiveness, Agribusiness Sub Terminal.

*)Dosen Pusat Pengembangan dan Pemberdayaan Pendidik dan Tenaga Kependdidikan (PPPPTK Pertanian).

**) Dosen Fakultas Sains Terapan UNSUR.

***) Alumni Fakultas Sains Terapan UNSUR.

PENGARUH PENERAPAN STANDARD OPERATING PROCEDURE (SOP) DAN KEBIJAKAN PERTANIAN TERHADAP EFEKTIVITAS LAYANAN SUB TERMINAL AGRIBISNIS (Studi Kasus di UPTD Sub Terminal Agribisnis dan Agropolitan Cigombong, Kecamatan Pacet, Kabupaten Cianjur)
ADANG SURYANA, ENDAH LISARINI dan ARISHA KONITA LARASATI 


\section{PENDAHULUAN}

Kebijakan petanian mengenai pemasaran hasil pertanian menurut Direktorat Jendral Pengolahan dan Pemasaran Hasil Pertanian Tahun 2015 yaitu salah satunya mengenai kebijakan pemasaran domestik. Berdasarkan UU No. 19 Tahun 2013 tentang Perlindungan dan Pemberdayaan Petani, menyatakan bahwa perlu adanya pengembangan sistem dan sarana dalam pemasaran domestik yang diselenggarankan melalui pembentukan Sub Terminal Agribisnis (STA). Selain daripada itu, Kebijakan pembentukan STA di Kabupaten Cianjur direalisasikan melalui Peraturan Bupati Cianjur Nomor 02 Tahun 2018 mengenai pembentukan Unit Pelaksana Teknis Daerah (UPTD) di lingkungan pemerintahan Kabupaten Cianjur. Aktivitas pemasaran produk pertanian melalui sarana pemasaran STA berkaitan dengan distribusi produk pertanian, merupakan satu aktivitas operasional dan rutin yang dilakukan STA. Sistem distribusi yang baik harus sesuai dengan standard operating procedure (SOP) yang telah ditetapkan organisasi.

Sub Terminal Agribinis (STA) di Kabupaten Cianjur berfokus pada tanaman hortikultura. STA ini memberikan layanan di antaranya sebagai tempat pemasaran produk, informasi 3pemasaran produk pertanian, dan tempat pendidikan bagi petani untuk memproduksi produknya lebih baik dan lebih berkualitas. Dari pemaparan tersebut, peneliti tertarik untuk mengkaji lebih jauh mengenai pengaruh penerapam SOP dan kebijakan pertanian terhadap efektivitas layanan, khususnya di STA Cigombong.

\section{Kebijakan Pertanian}

Menurut Hanafie (2014) bahwa istilah kebijakan sangat berkaitan terhadap suatu keputusan pemerintah. Hal ini karena, pemerintah memiliki wewenang dan kekuasaan dalam mengarahkan masyarakat serta bertanggungjawab dalam melayani kepentingan umum. Kebijakan publik merupakan sebagai salah satu keputusan yang dibuat oleh negara khususnya pemerintah sebagai strategi untuk merealisasikan tujuan negara yang bersangkutan (Menurut Nugroho, 2008). Sedangkan menurut Hanafie (2014) menyatakan bahwa kebijakan pertanian (agricultural policies) merupakan suatu serangkaian tindakan yang akan, sedang dan telah dilaksanakan oleh pemerintah untuk mencapai tujuan, sasaran melalui berbagai instrumen dan peraturan 24untuk kemudahan tataran operasional pembangunan pertanian di lapangan. Tujuan kebijakan pertanian diharapkan menghasilkan luaran tidak hanya meningkatkan produksi, akan tetapi juga mengupayakan untuk meningkatkan pendapatan petani (Nirwana, 2017).

Berdasarkan UU No. 19 Tahun 2013 tentang Perlindungan dan Pemberdayaan Petani perlu adanya pengembangan sistem dan sarana diselenggarankan melalui pasar tani atau pasar lelang, terminal agribisnis (TA), sub

\begin{tabular}{lll}
\hline PENGARUH & PENERAPAN & STANDARD \\
OPERATING & PROCEDURE & (SOP) DAN \\
KEBIJAKAN & PERTANIAN & TERHADAP \\
EFEKTIVITAS & LAYANAN SUB & TERMINAL \\
AGRIBISNIS (Studi Kasus di UPTD Sub & UPS Stisnis dan Agropolitan Cigombong, \\
Terminal Agribisnis & \\
Kecamatan Pacet, Kabupaten Cianjur)
\end{tabular}

ADANG SURYANA, ENDAH LISARINI dan ARISHA KONITA LARASATI 
terminal agribisnis (STA), Poktan PHP (Kelompok Tani Pemasaran Hasil Pertanian), pembatasan pasar modern, mengembangkan pola kemitraan usaha tani, mengembangkan sistem pemasaranmaupun promosi, menyediakan informasi pasar serta mengembangkan lindung nilai. Dalam penelitian ini, lebih spesifik membahas mengenai pembentukan STA di Kabupaten Cianjur yang terealisasi dalam Peraturan Bupati Cianjur Nomor 02 tahun 2018 tentang pembentukan Unit Pelaksana Teknis Daerah di lingkungan pemerintahan kabupaten Cianjur. Dalam PERBUP Cianjur No. 02 Tahun 2018 pasal 2 ayat (2) huruf e 3yang terdiri dari UPTD Kelas A pada Dinas Pertanian, Perkebunan, Pangan, dan Hortikultura salah satunya Sub Terminal Agribisnis dan Agropolitan (STA). UPTD Kelas A pada kabupaten/kota mewadahi beban kerja yang besar, meliputi wilayah kerja yang lebih dari 1 kecamatan pada UPTD STA dan Agropolitan meliputi wilayah Cipanas, Pacet, Sukaresmi, Cugenang, Warungkondang, Gekbrong, Campaka, Sukaluyu, dan Takokak serta jumlah beban kerjanya 10.000 (sepuluh ribu) atau lebih jam kerja efektif per tahun pada UPTD STA dan Agropolitan jumlah jam kerjanya 15.055 jam per tahun.

\section{Standard Operating Procedure (SOP)}

Standard Operating Procedure (SOP) yaitu serangkaian instruksi tertulis yang dibakukan mengenai berbagai proses penyelenggaraan aktivitas organisasi, bagaimana dan kapan harus dilakukan, dimana dan oleh siapa dilakukan (PERMENPAN-RB, 2012). Dalam 21Peraturan Menteri Pendayagunaan Aparatur Negara dan Rerformasi Birokrasi Republik Indonesia Nomor 35 tahun 2012 disebutkan bahwa prinsip pelaksanaan SOP yaitu :

1. Konsisten

SOP merupakan sutau hal yang harus dilaksanakan secara konsisten dari waktu ke waktu, oleh siapapun dan dalam kondisi apapun oleh seluruh jajaran organisasi pemerintah.

2. Komitmen

SOP merupakan sutau hal yang harus dilaksanakan dengan komitmen penuh dari seluruh jajaran organisasi, dari level paling rendah hingga tertinggi.

3. Perbaikan berkelanjutan

Pelaksanaan SOP tersebut harus dilaksanakan secara terbuka agar penyempurnaan-penyempurnaannya untuk memperoleh prosedur yang benarbenar efisien dan efektif.

4. Mengikat

SOP harus mengikat dalam pelaksana dan melaksanakan tugasnya sesuai dengan prosedur standar yang telah ditetapkan.

5. Seluruh unsur memiliki peran penting

Seluruh pegawai harus memiliki peran-peran tertentu dalam setiap prosedur yang distandarkan. Apabila pegawai tertentu tidak melaksanakan perannya dengan

\begin{tabular}{llc}
\hline PENGARUH & PENERAPAN & STANDARD \\
OPERATING & PROCEDURE & (SOP) DAN \\
KEBIJAKAN & PERTANIAN & TERHADAP \\
EFEKTIVITAS & LAYANAN SUB TERMINAL \\
AGRIBISNIS (Studi Kasus di UPTD Sub & UAdis \\
Terminal Agribisnis dan Agropolitan Cigombong, \\
Kecamatan Pacet, Kabupaten Cianjur)
\end{tabular}

ADANG SURYANA, ENDAH LISARINI dan ARISHA KONITA LARASATI 
baik, maka akan menganggu keseluruhan proses dan akhirnya berdampak pada proses penyelenggaraan pemerintahan.

6. Terdokumentasi dengan baik

Dalam seluruh prosedur yang telah distandarkan maka harus didokumentasikan secara baik agar dapat selalu dijadikan sebagai referensi bagi setiap yang memerlukannya.

SOP distribusi yaitu SOP tentang proses penyaluran produk mulai dari produsen hingga ke tangan konsumen yang perlu ditata dengan baik, akurat dan tepat waktu sehingga dapat mengurangi kesalahan pada proses distribusi dan membuat proses distribusi 29berjalan secara konsisten dan terstruktur (Winata, 2016). Menurut Peraturan Menteri Pertanian Nomor 19 tahun 2019 mengemukakan bahwa peningkatan mutu pasca panen produk pertanian harus didukung oleh penerapan SOP dalam hal ini kaitannya (Good Distribution Practices/GDP). GDP merupakan suatu prosedur yang bertujuan untuk mencegah proses pencemaran dari ketidaksesuaian baik proses penyaluran produk menurut kategori produk dan persyaratan produk termasuk saluran pemasaran (distribution channe) serta rantai dingin (cold chain) (Tobing, 2015).

\section{Efektivitas Layanan}

Menurut Kowaas (2017) mengemukakan bahwa efektivitas merupakan suatu unsur pokok untuk mencapai tujuan dan sasaran yang telah ditentukan di dalam setiap organisasi baik kegiatan maupun program. Suatu program dapat dikatakan efektif apabila mencapai tujuan dan sasaran akhir kebijakan. Menurut UndangUndang Nomor 25 Tahun 2009 mengenai pelayanan publik, menjelaskan bahwa pelayanan publik merupakan sebagai kegiatan atau rangkaian kegiatan dalam rangka pemenuhan kebutuhan pelayanan yang sesuai dengan peraturan perundang-undangan bagi setiap warga negara dan penduduk atas barang, jasa dan pelayanan administratif yang disediakan oleh penyelenggara pelayanan publik. Secara umum seluruh pelayanan publik yang diselenggarakan di Indonesia adalah tanggung jawab pemerintah, karena sebagai penyelenggara negara, pemerintah mengemban amanat undang-undang dasar negara (Hardiyansyah, 2017). Saat ini, manajemen pelayanan yang diberikan harus berorientasi pada kebutuhan, sehingga memiliki potensi untuk mendistribusikan perbedaan akses dan kualitas pelayanan kepada kelompok masyarakat yang berbeda (Dwiyanto, 2017). Apabila melihat pengertian efektivitas dan layanan 6di atas, maka dapat dikatakan bahwa efektivitas layanan adalah tercapainya suatu tujuan dan sasaran suatu organisasi dalam melakukan layanan sesuai dengan ketentuan yang telah ditetapkan.

\begin{tabular}{llc}
\hline PENGARUH & PENERAPAN & STANDARD \\
OPERATING & PROCEDURE & (SOP) DAN \\
KEBIJAKAN & PERTANIAN & TERHADAP \\
EFEKTIVITAS LAYANAN SUB & TERMINAL \\
AGRIBISNIS (Studi Kasus di UPTD Sub \\
Terminal Agribisnis dan Agropolitan Cigombong, \\
Kecamatan Pacet, Kabupaten Cianjur)
\end{tabular}

ADANG SURYANA, ENDAH LISARINI dan ARISHA KONITA LARASATI 


\section{Sub Terminal Agribisnis (STA)}

Sub Terminal Agribisnis (STA) menurut Direktorat Jenderal Pengelolaan dan Pemasaran Hasil Pertanian (2015) merupakan suatu tempat/sarana pemasaran yang dibangun secara spesifik untuk melayani dan melaksanakan kegiatan distribusi dan pemasaran hasil petanian petani atau pelaku usaha pertanian dari sumber produksi ke lokasi tujuan pemasaran. Tujuan dibentuknya Sub Terminal Agribisnis (STA) menurut Direktorat Jenderal Hortikultura tentang Petunjuk Teknis Pengolahan dan Pemasaran Hasil Hortikultura (2019) adalah untuk menyediakan fasilitas, pembinaan, pengawalan, dan pendampingan, serta bimbingan teknis pengembangan pemasaran komoditas hortikultura, meningkatkan dan menguatkan akses pemasaran komoditas hortikultura pada tingkat farm gate, pasar domestik, dan internasional, memperkuat kelembagaan pemasaran pada tingkat farm gate, dan mengembangkan dan mengoptimalkan pelayanan informasi pemasaran komoditas hortikultura.

Sedangkan, sasaran utama pembangunan Sub Terminal Agribisnis pada dasarnya adalah untuk meningkatkan pemasaran komoditas hortikultura lokal di pasar domestik, meningkatkan ekspor produk hortikultura di pasar internasional, memotong atau memperpendek mata rantai pemasaran, stabilitas harga komoditas hortikultura unggulan, tersediannya data dan informasi 14pemasaran yang cepat, tepat, akurat, up to date, dan kontinyu, tersebarnya informasi pemasaran meliputi informasi harga, informasi pemasok, biaya usahatani, biaya pemasaran, dan data supplier, dan peningkatkan kredibilitas dan kinerja petugas PIP dan Analisis 1Pemasaran Hasil Pertanian (APHP). Pelayanan di STA Cigombong terdiri dari sarana dan 19prasarana pasca panen seperti kantor, tempat pengumpulan produk tempat pencucian, gudang pendingin, tempat sortasi, pengemasan, dan pelabelan serta sortasi (Shiddieqy dan Widiani, 2015).

\section{METODE PENELITIAN}

Penelitian ini dilakukan di Unit Pelaksana Teknis Daerah Sub Terminal Agribisnis dan Agropolitan Cigombong, Kecamatan Pacet, Kabupaten Cianjur. Waktu pelaksanaan penelitian dimulai pada bulan Februari 2020 sampai dengan bulan Agustus 2020. Populasi dan sampel dalam penelitian ini berjumlah 66 orang petani yang memasok sayuran ke pelaku usaha di STA untuk didistribusikan kembali ke pasar tradisional. Data untuk menunjang penelitian ini 3diperoleh dari observasi, wawancara ke Dinas Pertanian, Perkebunan, Pangan, dan Hortikultura, UPTD STA dan Agropolitas, pelaku usaha di STA, dan petani, dan kuesioner tentang pendapat petani berkenaan dengan variabel penelitian. Variabel penelitian, konsep variabel, dimensi, indikator variabel, dan skala pengukuran dapat dilihat pada Tabel 1.

Untuk mengetahui pengaruh parsial maupun simultan dari variabel endogen terhadap variabel eksogen, dilakukan analisis jalur. Sebelumnya, data yang diolah

\begin{tabular}{llc}
\hline PENGARUH & PENERAPAN & STANDARD \\
OPERATING & PROCEDURE & (SOP) DAN \\
KEBIJAKAN & PERTANIAN & TERHADAP \\
EFEKTIVITAS LAYANAN SUB & TERMINAL \\
AGRIBISNIS (Studi Kasus di UPTD Sub \\
Terminal Agribisnis dan Agropolitan Cigombong, \\
Kecamatan Pacet, Kabupaten Cianjur)
\end{tabular}

ADANG SURYANA, ENDAH LISARINI dan ARISHA KONITA LARASATI 
sudah terlebih dahulu diuji validitas untuk menguji validitas digunakan kolom Corrected Item-Total Correlation, jika nilai pada kolom tersebut $>$ nilai cut off 0,300 maka item tersebut valid (Heryanto dan Triwibowo, 2018). Sedangkan untuk menguji reliabilitas Sani dan Mashuri (2010) berpendapat bahwa bila nilai dari chronbach's alpha (a) > 60\% $(0,60)$ maka variabel tersebut dikatakan reliabel. Selanjutnya, data tapat diuji lebih lanjut untuk uji $\mathrm{F}$, uji t, analisis jalur, dan koefisien determinasi.

Tabel 1 Operasional Variabel.

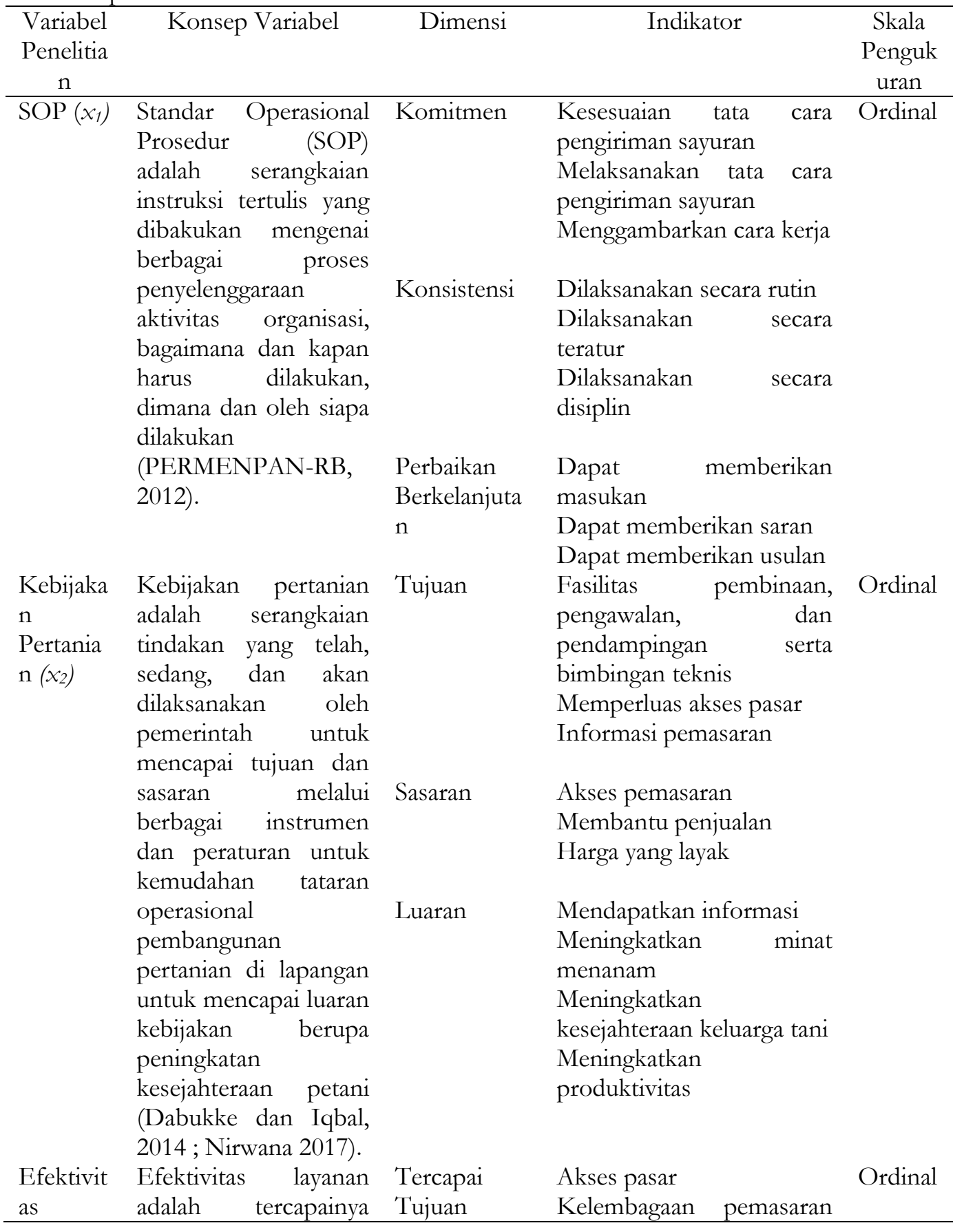

\begin{tabular}{llc}
\hline PENGARUH & PENERAPAN & STANDARD \\
OPERATING & PROCEDURE & (SOP) DAN \\
KEBIJAKAN & PERTANIAN & TERHADAP \\
EFEKTIVITAS LAYANAN SUB & TERMINAL \\
AGRIBISNIS (Studi Kasus di UPTD Sub \\
Terminal Agribisnis dan Agropolitan Cigombong, \\
Kecamatan Pacet, Kabupaten Cianjur)
\end{tabular}

ADANG SURYANA, ENDAH LISARINI dan ARISHA KONITA LARASATI 


$\begin{array}{ll}\text { Layanan } & \text { suatu tujuan dan } \\ \text { (Y) } & \text { sasaran dari organisasi } \\ & \text { dalam melakukan } \\ & \text { layanan sesuai dengan } \\ & \text { ketentuan yang telah } \\ \text { ditetapkan (Kowaas, } & \text { 2017; Lembaga } \\ & \text { Administrasi Negara, } \\ & \text { 2016). }\end{array}$

\begin{tabular}{|c|c|}
\hline \multirow{3}{*}{$\begin{array}{l}\text { Tercapai } \\
\text { Komitmen }\end{array}$} & Layanan sesuai harapan \\
\hline & Layanan tertib \\
\hline & Layanan teratur \\
\hline \multicolumn{2}{|l|}{ Tercapai } \\
\hline Luaran & Mewujudkan kesejahteraan \\
\hline Penerapan & Meningkatkan pendapatan \\
\hline
\end{tabular}

\section{HASIL DAN PEMBAHASAN}

Dari data yang diperoleh mayoritas karakteristik responden berdasarkan jenis kelamin adalah laki-laki sebesar 91\%, berdasarkan usia 41-50 tahun sebesar 41\%, pendidikan terbanyak sekolah dasar sebesar $48 \%$, dan lama memasok lebih dari 5 tahun sebesar $62 \%$. Hal ini mencerminkan bahwa memang petani merupakan tulang punggung keluarga dalam rentan usia produktif dan didukung oleh keadaan geografis daerah sekitaran STA cocok untuk ditanami sayuran, akan tetapi pendidikan petani yang masih terbilang cukup rendah membuat petani memerlukan waktu saat menerapkan pengembangan manajemen usahatani. Guna menjawab tujuan penelitian dilakukan pengujian deskriptif kuantitatif dengan menggunakan analisis jalur. Langkah awal dilakukann uji validitas dan reliabilitas terhadap data SOP, kebijakan pertanian, dan efektivitas layanan. Hasil yang didapat berturut-turut ditunjukkan pada Tabel 2., Tabel 3., Tabel 4., dan Tabel 5.

Tabel 2. Hasil Uji Validitas Standard Operating Procedure

\begin{tabular}{cccc}
\hline Item & $\boldsymbol{r}$ hitung & Cut-Off & Hasil \\
\hline$x_{1.1}$ & 0,373 & 0,300 & Valid \\
$x_{1.2}$ & 0,564 & 0,300 & Valid \\
$x_{1.3}$ & 0,388 & 0,300 & Valid \\
$x_{1.4}$ & 0,564 & 0,300 & Valid \\
$x_{1.5}$ & 0,418 & 0,300 & Valid \\
$x_{1.6}$ & 0,589 & 0,300 & Valid \\
$x_{1.7}$ & 0,651 & 0,300 & Valid \\
$x_{1.8}$ & 0,608 & 0,300 & Valid \\
$x_{1.9}$ & 0,501 & 0,300 & Valid \\
\hline
\end{tabular}

Sumber : Data Olahan, 2020.

\begin{tabular}{lll}
\hline PENGARUH & PENERAPAN & STANDARD \\
OPERATING & PROCEDURE & (SOP) DAN \\
KEBIJAKAN & PERTANIAN & TERHADAP \\
EFEKTIVITAS & LAYANAN SUB & TERMINAL \\
AGRIBISNIS (Studi Kasus di & UPTD Sub \\
Terminal Agribisnis dan Agropolitan Cigombong, \\
Kecamatan Pacet, Kabupaten Cianjur)
\end{tabular}

ADANG SURYANA, ENDAH LISARINI dan ARISHA KONITA LARASATI 
Tabel 3. Uji Validitas Kebijakan Pertanian.

\begin{tabular}{cccc}
\hline Item & $\boldsymbol{r}$ hitung & Cut-Off & Hasil \\
\hline$x_{2.1}$ & 0,455 & 0,300 & Valid \\
$x_{2.2}$ & 0,436 & 0,300 & Valid \\
$x_{2.3}$ & 0,367 & 0,300 & Valid \\
$x_{2.4}$ & 0,414 & 0,300 & Valid \\
$x_{2.5}$ & 0,346 & 0,300 & Valid \\
$x_{2.7}$ & 0,550 & 0,300 & Valid \\
$x_{2.8}$ & 0,630 & 0,300 & Valid \\
$x_{2.9}$ & 0,685 & 0,300 & Valid \\
$x_{2.10}$ & 0,733 & 0,300 & Valid \\
\hline
\end{tabular}

Sumber : Data Olahan, 2020.

Tabel 4. Uji Validitas Efektivitas Layanan.

\begin{tabular}{cccc}
\hline Item & $\boldsymbol{r}$ hitung & Cut-Off & Hasil \\
\hline$Y_{1}$ & 0,645 & 0,300 & Valid \\
$Y_{2}$ & 0,693 & 0,300 & Valid \\
$Y_{3}$ & 0,508 & 0,300 & Valid \\
$Y_{4}$ & 0,525 & 0,300 & Valid \\
$Y_{5}$ & 0,670 & 0,300 & Valid \\
$Y_{6}$ & 0,479 & 0,300 & Valid \\
$Y_{7}$ & 0,654 & 0,300 & Valid \\
$Y_{8}$ & 0,637 & 0,300 & Valid \\
$Y_{9}$ & 0,511 & 0,300 & Valid \\
$Y_{10}$ & 0,633 & 0,300 & Valid \\
$Y_{11}$ & 0,677 & 0,300 & Valid \\
$Y_{12}$ & 0,625 & 0,300 & Valid \\
$Y_{13}$ & 0,613 & 0,300 & Valid \\
$Y_{14}$ & 0,633 & 0,300 & Valid \\
\hline
\end{tabular}

Sumber : Data Olahan, 2020.

Setelah dilakukan pengujian validitas data dapat diolah lebih lanjut, untuk data yang tidak valid tidak diikutsertakan dalam pengujian selanjutnya.

Tabel 5. Hasil Uji Reliablitias SOP, kebijakan pertanian, dan efektivitas layanan

\begin{tabular}{ccc}
\hline Var. & Chronbach's Alpha & Cut-Off \\
\hline SOP $\left(\mathbf{x}_{\mathbf{1}}\right)$ & 0,814 & 0,600 \\
KP $\left(\mathbf{x}_{\mathbf{2}}\right)$ & 0,824 & 0,600 \\
EL $(\boldsymbol{Y})$ & 0,903 & 0,600 \\
\hline
\end{tabular}

Sumber : Data Olahan, 2020.

Hasil pengujian reabilitas menunjukkan nilai Chronbach's Alpha $>0,600$, sehingga semua variabel yang digunakan reliabel untuk diolah lebih lanjut.

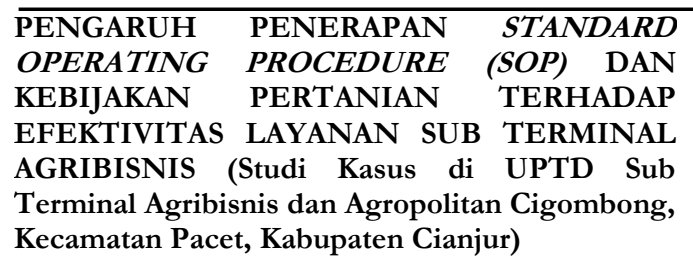


Tabel 6. Hasil Uji Hipotesis Secara Keseluruhan atau Simultan (Uji F).

ANOVA $^{a}$

\begin{tabular}{|c|c|c|c|c|c|c|}
\hline \multicolumn{2}{|c|}{ Model } & Sum of Squares & Df & Mean Square & $\mathbf{F}$ & Sig. \\
\hline \multirow{3}{*}{1} & Regression & 1672.397 & 2 & 836.199 & 70.142 & $.000^{\mathrm{b}}$ \\
\hline & Residual & 727.212 & 61 & 11.922 & & \\
\hline & Total & 2399.609 & 63 & & & \\
\hline
\end{tabular}

a. Dependent Variable: Efektivitas Layanan

b. Predictors: (Constant), Kebijakan Pertanian, Standar Operasional Prosedur Sumber : Data Olahan, 2020.

Hasil perhitungan dengan IBM SPSS didapatkan angka $F_{\text {hitung }}$ sebesar 70,142 dan $\mathrm{F}_{\text {hitung }}$ sebesar 3,993, maka $\mathrm{F}_{\text {hitung }}>\mathrm{F}_{\text {tabel }}$ yang artinya $\mathrm{H}_{0}$ ditolak dan $\mathrm{H}_{1}$ diterima dan nilai sig. pada tabel sebesar $0,000<0,05$. Artinya, ada pengaruh signifikan SOP $\left(x_{1}\right)$ dengan kebijakan pertanian $\left(x_{2}\right)$ terhadap efektivitas layanan $(Y)$. Kesimpulannya ialah variabel SOP dan kebijakan pertanian berpengaruh signifikan secara simultan terhadap variabel efektivitas layanan. Petani merasa layanan yang diberikan oleh STA sudah efektif apalagi setelah dibentuk UPTD STA dan proses penyaluran produk berpedoman pada SOP. Petani merasa informasi distribusi di STA ini juga sangat transparan, sebab harga selalu ditampilkan di layar monitor di depan gerbang STA serta tujuan pasar dari sayuran yang petani kirim diberitahukan sebelumnya beserta jam pengiriman sayuran. Namun, disisi lain petani juga masih mengharapkan pemerintah memberikan kontribusi pada pembelian sayuran petani, agar harga yang diterima lebih tinggi daripada harga saat ini

Tabel 7. Hasil Uji Secara Individu (Uji t)

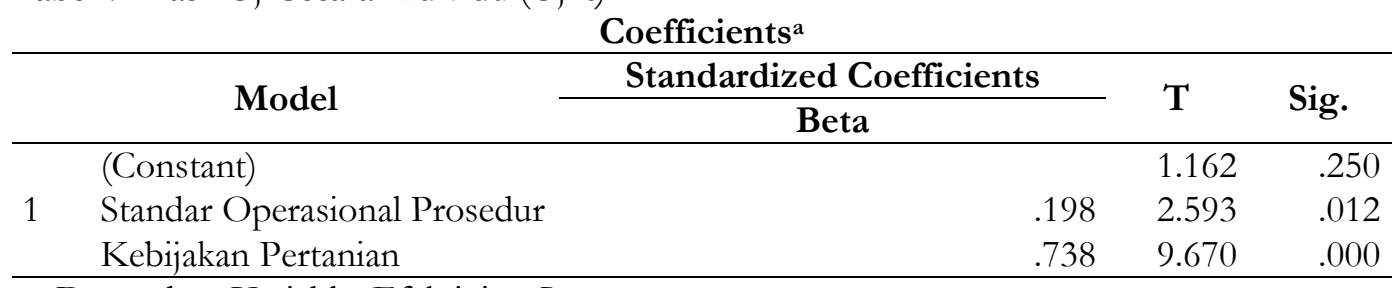

a. Dependent Variable: Efektivitas Layanan

Sumber : Data Olahan, 2020.

Hasil perhitungan IBM SPSS 21 menunjukkan nilai t hitung sebesar 2,593 > t tabel sebesar 1,998. Sehingga dapat disimpulkan bahwa $\mathrm{H}_{0}$ ditolak dan $\mathrm{H}_{1}$ diterima. Artinya, ada pengaruh signifikan SOP terhadap efektivitas layanan. Besar pengaruh variabel SOP ialah 0,198, pengaruh ini signifikan terhadap variabel efektivitas layanan karena nilai siginifikansi sebesar 0,012<0,05. Pengaruh kecil dan signifikan dari SOP terhadap efektivitas layanan sejalan dengan penelitian dari Maulidya dan Meilani (2014), bahwa SOP yang diterapkan di sudah dijalankan dengan baik, namun belum memberikan hasil yang optimal pada efektivitas pelayanan publik. Petani menjalankan SOP yang diterapkan agar dapat mengefektifkan waktu, karena petani sudah mendapatkan informasi pemesanan sayuran baik volume maupun lokasi tujuan

\begin{tabular}{llc}
\hline PENGARUH & PENERAPAN & STANDARD \\
OPERATING & PROCEDURE & (SOP) DAN \\
KEBIJAKAN & PERTANIAN & TERHADAP \\
EFEKTIVITAS LAYANAN SUB & TERMINAL \\
AGRIBISNIS (Studi Kasus di UPTD Sub \\
Terminal Agribisnis dan Agropolitan Cigombong, \\
Kecamatan Pacet, Kabupaten Cianjur)
\end{tabular}

ADANG SURYANA, ENDAH LISARINI dan ARISHA KONITA LARASATI 
pengiriman sayuran. Namun, melihat pelaksanaan SOP dilapangan tidak semua petani menerapkan SOP setiap hari sebab, keterbatasan kemampuan petani baik pada sortasi produk maupun penyediaan produk.

Selanjutnya, untuk melihat pengaruh variabel kebijakan pertanian terhadap variabel efektivitas layanan hasil perhitungan IBM SPSS 21 menunjukkan nilai $\mathrm{t}$ hitung sebesar 9,670 > t tabel sebesar 1,998 Sehingga dapat disimpulkan bahwa $\mathrm{H}_{0}$ ditolak dan $\mathrm{H}_{1}$ diterima. Artinya, ada pengaruh signifikan varibel kebijakan pertanian terhadap variabel efektivitas layanan. Besar pengaruh variabel SOP ialah 0,738, pengaruh ini signifikan terhadap variabel efektivitas layanan karena nilai siginifikansi sebesar $0,000<0,05$.

Hasil penelitian menujukkan kesamaan dengan penelitian dari Kori,dkk (2015) bahwa perapan kebijakan reformasi birokrasi dapat meningkatkan efektivitas dari sebuah organisasi pemerintahan dalam memberikan layanan kepada masyarakat. Hal ini dikarenakan kebijakan pertanian berkenaan dengan pembentukan STA dan direalisasikan di tingkat kabupaten/kota khususnya di Kabupaten Cianjur dengan pembentukan UPTD STA membuat layanan STA kepada petani menjadi lebih baik dengan trasparansi pihak STA kepada petani sebagai salah satu pengguna layanan STA, sehingga saat petani menjual hasil panen kepada pelaku usaha terjadi transaksi yang jelas dan tidak terjadi kecurangan berkenaan dengan harga dan sistem pembayaran secara langsung. Mayoritas petani beranggapan bahwa saat ini yang dibutuhkan bukan pelatihan ataupun seminar tetapi akses pemasaran produk pertanian dengan harga menjanjikan dan dapat meningkatkan kesejahteraan para petani. Hal ini sejalan, dengan masih panjangnya rantai pemasaran sayuran akibat dari pelaku usaha yang memasok sayuran ke pasar tradisional menjual sayuran kepada pedagang besar atau ke pengecer tidak dijual langsung kepada konsumen, sehingga harga yang diterima petani relatif hampir sama dengan saat menjual ke tengkulak lain.

Tabel 8. Hasil Uji R Square

Model Summary

\begin{tabular}{lccccc}
\hline Model & $\mathbf{R}$ & R Square & $\begin{array}{c}\text { Adjusted R } \\
\text { Square }\end{array}$ & $\begin{array}{c}\text { Std. Error of the } \\
\text { Estimate }\end{array}$ & $\begin{array}{c}\text { Durbin- } \\
\text { Watson }\end{array}$ \\
\hline 1 & $.835^{\mathrm{a}}$ & .697 & .687 & 3.453 & 2.021 \\
\hline a. Predictors: (Constant), Kebijakan Pertanian, Standar Operasional Prosedur & \\
b. Dependent Variable: Efektivitas Layanan \\
Sumber: Data Olahan, 2020.
\end{tabular}

Pengaruh error dalam analisis jalur SOP dan kebijakan pertanian terhadap efektivitas layanan dapat dihitung dengan rumus sebagai berikut:

$\mathrm{e}=1-\mathrm{R}^{2}$

$\mathrm{e}=1-0,697$

$\mathrm{e}=0,303 \times 100 \%$

$\mathrm{e}=30,3 \%$

\begin{tabular}{lll}
\hline PENGARUH & PENERAPAN & STANDARD \\
OPERATING & PROCEDURE & (SOP) DAN \\
KEBIJAKAN & PERTANIAN TERHADAP \\
EFEKTIVITAS LAYANAN SUB & TERMINAL \\
AGRIBISNIS (Studi Kasus di UPTD Sub \\
Terminal Agribisnis dan Agropolitan Cigombong, \\
Kecamatan Pacet, Kabupaten Cianjur)
\end{tabular}

ADANG SURYANA, ENDAH LISARINI dan ARISHA KONITA LARASATI 


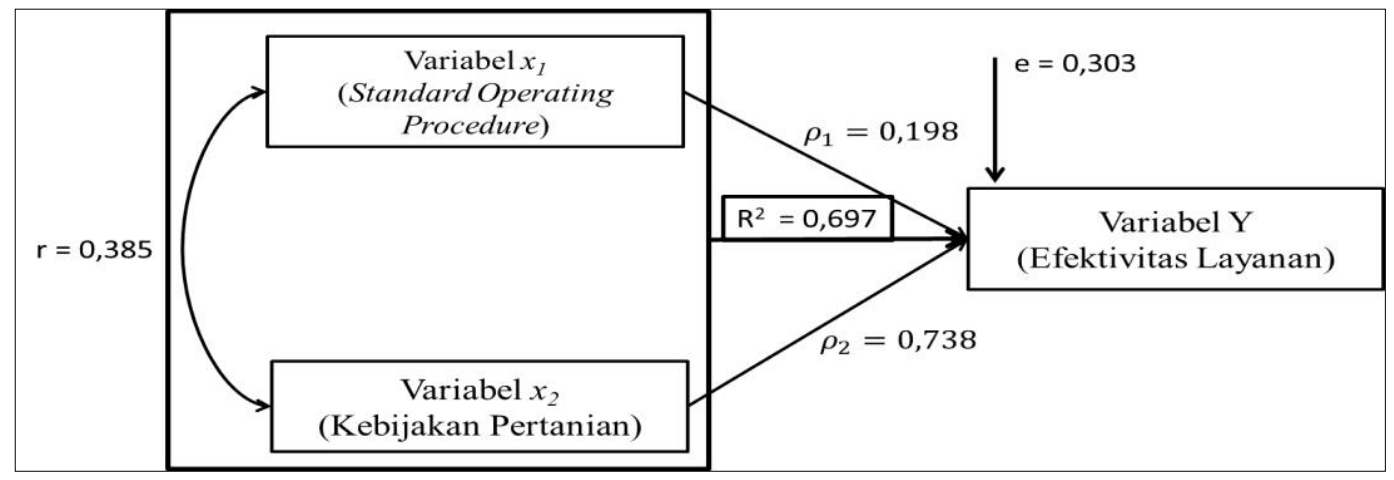

$$
\begin{gathered}
\text { Gambar 1. Diagram Jalur } \\
\text { Sumber : Data Olahan, } 2020 \\
\text { Efektivitas layanan }=0,198_{\text {SOP }}+0,738_{\text {kebijakan pertanian }}+0,303
\end{gathered}
$$

SOP memberikan kontribusi yang jauh lebih kecil dibandingkan dengan kebijakan pertanian terhadap efektivitas layanan, karena struktur STA yang belum lengkap terutama pada bidang pengelola terminal agribisnis dan pendataan distribusi komoditi pertanian dan perkebunan yang bertanggung jawab atas sistem distribusi di STA membuat SOP ini belum optimal dilaksanakan dilapangan. Di bagian kelengkapan SOP hanya sekedar diagram alir belum dilengkapi dengan instruksi kerja dan form laporan, sehingga untuk pelaku usaha dan petani baru yang bergabung masih kebingungan untuk melaksanakan SOP.

Selain itu, petani masih dalam tahap membiasakan diri menggunakan SOP yang diterapkan oleh STA, sesuai dengan data lapangan bahwa mayoritas petani berpendidikan SD maka perlua adanya waktu dalam mendidik petani untuk menyesuaikan perbedaan memasok ke STA saat belum menggunakan SOP dan setelah ada SOP. Sebaliknya, kontribusi yang besar dari kebijakan pertanian terhadap efektivitas layanan UPTD STA lebih memperhatikan mencapai tujuan dan sasaran pembentukan STA secara nasional. Selain itu, petani merasakan layanan yang diberikan STA semakin efektif setelah dibentuk UPTD STA. Hal ini dikarenakan petani bisa mendapatkan pelatihan apabila petani inginkan untuk mengikuti kegiatan, petani juga mendapatkan akses pasar yang lebih luas bagi hasil pertanian mereka hingga ke luar Cianjur, dan petani bisa meminta informasi pemasaran produk pertanian kepada STA bila petani ingin menjadi pelaku usaha pertanian juga disamping hanya menjadi petani.

Tabel 9. Interpretasi Koefisien Korelasi.

\begin{tabular}{ll}
\hline \multicolumn{1}{c}{ Interval Koefisien } & \multicolumn{1}{c}{ Tingkat Hubungan } \\
\hline $0,00-0,199$ & Sangat rendah \\
$0,20-0,399$ & Rendah \\
$0,40-0,599$ & Sedang \\
$0,60-0,799$ & Kuat \\
$0,80-1,000$ & Sangat Kuat \\
\hline
\end{tabular}

Sumber : Sugiyono, 2019.

\begin{tabular}{lll}
\hline PENGARUH & PENERAPAN & STANDARD \\
OPERATING & PROCEDURE & (SOP) DAN \\
KEBIJAKAN & PERTANIAN TERHADAP \\
EFEKTIVITAS LAYANAN SUB & TERMINAL \\
AGRIBISNIS (Studi Kasus di UPTD Sub \\
Terminal Agribisnis dan Agropolitan Cigombong, \\
Kecamatan Pacet, Kabupaten Cianjur)
\end{tabular}

PENGARUH PENERAPAN STANDARD KEBIJAKAN PERTANIAN TERHADAP EFEKTIVITAS LAYANAN SUB TERMINAL Terminal Agribisnis dan Agropolitan Cigombong, Kecamatan Pacet, Kabupaten Cianjur) 
Selanjutnya, hubungan atau korelasi variabel SOP $\left(x_{1}\right)$ dengan variabel kebijakan pertanian $\left(x_{2}\right)$ sebesar 0,385 , termasuk dalam kategori rendah. Jadi terdapat hubungan yang rendah/lemah antara SOP dengan kebijakan pertanian . hubungan yang lemah ini menurut data lapangan terjadi karena STA lebih memperhatikan kebijakan pertanian yang berskala nasional, sedangkan SOP dibiarkan berjalan dengan penerapan sedikit demi sedikit kepada petani. SOP ini belum secara tegas diberlakukan oleh STA, sebab STA menghargai keterbatasan petani dalam menjalankan SOP di lapangan. Selain itu, kebiasaan masyarakat Indonesia yang lebih patuh terhadap kebijakan daripada teknis dilapangan membuat hubungan SOP dan kebijakan pertanian lemah.

Tabel 10. Hasil Uji R Square.

\begin{tabular}{lrrrrr}
\multicolumn{6}{c}{ Model Summary $^{\mathbf{b}}$} \\
\hline Model & R & R Square & $\begin{array}{c}\text { Adjusted R } \\
\text { Square }\end{array}$ & $\begin{array}{c}\text { Std. Error of the } \\
\text { Estimate }\end{array}$ & $\begin{array}{c}\text { Durbin- } \\
\text { Watson }\end{array}$ \\
\hline 1 & $.835^{\mathrm{a}}$ & .697 & .687 & 3.453 & 2.021 \\
\hline
\end{tabular}

a. Predictors: (Constant), Kebijakan Pertanian, Standar Operasional Prosedur

b. Dependent Variable: Efektivitas Layanan

Data Olahan, 2020.

Kedua variabel (SOP dan kebijakan pertanian) mampu menjelaskan variabel efektivitas layanan sebesar $69,7 \%$. Hal ini berarti pengaruh antara variabel eksogenus dan variabel endogenus sebesar $69,7 \%$. Dari angka tersebut dapat diambil kesimpulan bahwa pengaruh antara variabel eksogenus dan endogenus hampir mendekati 1. Sedangkan, hasil perhitungan diperoleh nilai error sebesar 0,303, artinya ada 30,3\% dijelaskan oleh variabel bebas lainnya yang tidak diteliti oleh peneliti dalam penelitian, peneliti beranggapan pengaruh lain yang tidak diteliti tersebut berkenaan dengan harga, kesadaran petani dan pelaku usaha, kebijakan subsidi, struktur organisasi, kinerja pelaku usaha, rantai pemasaran, peranan koperasi.

\section{PENUTUP}

\section{Kesimpulan}

Berdasarkan uraian pada hasil penelitian, maka dapat ditarik kesimpulan bahwa:

1. Variabel Standard Operating Procedure (SOP) $\left(x_{1}\right)$ berpengaruh signifikan terhadap variabel efektivitas layanan $(Y)$.

2. Variabel kebijakan pertanian $\left(x_{2}\right)$ berpengaruh signifikan terhadap variabel efektivitas layanan $(Y)$.

3. Variabel SOP $\left(x_{1}\right)$ dan kebijakan pertanian $\left(x_{2}\right)$ berpengaruh signifikan secara simultan terhadap variabel efektivitas layanan $(Y)$.

\begin{tabular}{llc}
\hline PENGARUH & PENERAPAN & STANDARD \\
OPERATING & PROCEDURE & (SOP) DAN \\
KEBIJAKAN & PERTANIAN & TERHADAP \\
EFEKTIVITAS LAYANAN SUB & TERMINAL \\
AGRIBISNIS (Studi Kasus di UPTD Sub \\
Terminal Agribisnis dan Agropolitan Cigombong, \\
Kecamatan Pacet, Kabupaten Cianjur)
\end{tabular}

ADANG SURYANA, ENDAH LISARINI dan ARISHA KONITA LARASATI 


\section{Saran}

Adapun saran yang dapat penulis berikan sesuai hasil penelitian adalah sebagai berikut :

1. Bagi Dinas Pertanian, Perkebunan, Pangan, dan Hortikultura Kabupaten Cianjur dapat melengkapi struktur organisasi dari UPTD STA dan Agropolitan, sehingga SOP distribusi yang dijalankan sesuai dan kebijakan pembentukan STA agar efektivitas layanan semakin meningkat.

2. Bagi STA sebagai pengelola diharapkan terus melakukan perbaikan berkenaan dengan SOP distribusi dengan melengkapi instruksi kerja dan form laporan harian, sehingga dapat mempermudah pelaku usaha dan pertani untuk mengerjakan SOP yang diterapkan. Selain itu, STA juga diharapkan mengoptimalkan keberadaan koperasi sehingga, SOP ditribusi dan kebijakan pembentukan STA ini dapat meningkatkan efektvitas layanan terutama pada pemasaran hasil dapat secara rutin melakukan ekspor produk hortikultura.

3. Bagi pelaku usaha diharapkan dapat lebih mematuhi SOP dalam menjalankan kegiatan distribusi dan memberikan masukan agar SOP distribusi lebih memperhatikan keterbatasan petani di lapangan.

4. Bagi petani pemasok diharapkan terus memberikan saran dan kritik kepada STA berkenaan dengan SOP dan kebijakan pertanian supaya petani mendapatkan layanan yang semakin efektif dari STA.

\section{DAFTAR PUSTAKA}

Direktorat Jenderal Hortikultura. (2019). Petunjuk Teknis Pengolahan dan Pemasaran Hasil Hortikultura Tabun 2019. Jakarta : Kementerian Pertanian.

Direktorat Jenderal Pengolahan dan Pemasaran Hasil Pertanian. (2015). Pedoman Umum Kegiatan Pembangunan Pengolahan Dan Pemasaran Hasil Pertanian Tabun Anggaran 2015. Jakarta : Kementerian Pertanian.

Dwiyanto, Agus. (2017). Manajemen Pelayanan Publik : Peduli, Inklusif, Dan Kolaboratif. Yogyakarta : Gadjah Mada University Press.

Hanafie, Rita. (2014). Pengantar Ekonomi Pertanian. Yoyakarta : Penerbit ANDI.

Hardiyansyah. (2017). Manajemen Pelayanan dan Pengembangan Organisasi Publik Dalam Perspektif Riset Ilmu Administrasi Publik Kontemporer. Yogyakarta : Gava Media.

Heryanto, Imam. dan Triwibowo, Totok. (2018). Path Analysis Menggunakan SPSS dan Excel Panduan Pengolahan Data Penelitian Untuk Skripsi/Tesis. Bandung : Informatika.

Kowaas, Agrio Scivo. (2017). Efektivitas Pelaksanaan Tomohon International Festival Di Kota Tomohon. Ejournal Universitas Sam Ratulangi.

Nirwana, Nita. (2017). Deskripsi Sosial Ekonomi Keluarga Petani Gurem di Desa Sidosari Kecamatan Natar Kabupaten Lampung Selatan Tahun 2017. Skripsi.

\begin{tabular}{llc}
\hline PENGARUH & PENERAPAN & STANDARD \\
OPERATING & PROCEDURE & (SOP) DAN \\
KEBIJAKAN & PERTANIAN & TERHADAP \\
EFEKTIVITAS LAYANAN SUB & TERMINAL \\
AGRIBISNIS (Studi Kasus di UPTD Sub \\
Terminal Agribisnis dan Agropolitan Cigombong, \\
Kecamatan Pacet, Kabupaten Cianjur)
\end{tabular}

ADANG SURYANA, ENDAH LISARINI dan ARISHA KONITA LARASATI 
Fakultas Keguruan dan Ilmu Pendidikan Universitas Lampung. Lampung. Dipublikasikan.

Nugroho, Riant. (2008). Public Policy. Jakarta : PT. Elex Media Komputindo.

Peraturan Bupati Cianjur Nomor 02 Tahun 2018 Tentang Pembentukan Unit

Pelaksana Teknis Daerah Di Lingkungan Pemerintahan Kabupaten Cianjur.

Peraturan Menteri Pendayagunaan Aparatur Negara dan Reformasi Birokrasi Nomor

35 Tahun 2012 Tentang Pedoman Penyusunan Standar Operasional Prosedur

Administrasi Pemerintah.

Peraturan Menteri Pertanian Nomor 19 Tahun 2019 Tentang Pengembangan Ekspor Komoditas Pertanian.

Sani dan Mashuri. (2010). Metodologi Riset Manajemen Sumber Daya Manusia, Malang : UIN Malang Press.

Shidqqieqy, Megawati. dan Widiani, Wiwin. (2012). Kontribusi Penanganan Pasca

Panen Worter Terhadap Pendapatan Petani Sayuran Binaan Sub Terminal

Agribisnis (STA) Cigombong Desa Ciherang Kabupaten Cianjur. Journal Of Agroscience

Tobing, Bortiandy. (2015). Rantai Pasok Pangan (Food Supply Chain). Jurnal Supply Chain Indonesia.

Undang-Undang Nomor 19 tahun 2013 tentang Perlindungan dan Pemberdayaan Petani.

Undang-Undang Nomor 25 Tahun 2009 Tentang Pelayanan Publik.

Winata, Sheila Vania. (2016). Perancangan Standard Operating Procedure (SOP) Pada Chocolab. Performa Jurnal Manajemen dan Start-Up Bisnis.

PENGARUH PENERAPAN STANDARD OPERATING PROCEDURE (SOP) DAN KEBIJAKAN PERTANIAN TERHADAP EFEKTIVITAS LAYANAN SUB TERMINAL AGRIBISNIS (Studi Kasus di UPTD Sub Terminal Agribisnis dan Agropolitan Cigombong, Kecamatan Pacet, Kabupaten Cianjur)
ADANG SURYANA, ENDAH LISARINI dan ARISHA KONITA LARASATI 